Ricardo Guerrero - Rubens López

\title{
A brief history of the journal(s) of the SEM: staunchly resisting against improbability. II. From 1998 to 2002
}

Published online: 14 June 2003

(C) Springer-Verlag and SEM 2003

\section{A new-old journal: International Microbiology}

As we mentioned at the end of the first article of this brief history [9], International Microbiology, the new journal of the Spanish Society for Microbiology (SEM), started in 1998. During the first 3 years of publication, this journal was produced by the Spanish branch of Springer-Verlag, located in Barcelona, where the editorial office of the journal had resided since 1994. Francisco Ruiz Berraquero, SEM president in 1998, was very helpful in the establishment of the contract with the new publisher; and the journal soon recovered its publication pace. In 2001, however, Springer-Verlag gave up publishing journals or books at its Spanish branch; and, since then, International Microbiology has been produced by SpringerVerlag in Heidelberg, Germany. Although the format of International Microbiology differs greatly from the previous SEM journals (Fig. 1), it has kept their general structure, with several distinct sections. Editorials are usually written by experts who are requested to give their own opinion on the field in which they work.

The Editorial Board was enlarged and now, for each field of expertise, there are both a Spanish and a foreign member. The most characteristic physical feature of the journal is now its cover, which integrates the different groups of organisms studied in microbiology: viruses, prokaryotes (either Bacteria or Archaea), protists and fungi. A picture of each group is always present on the cover throughout the year. In the middle, there is a round, actual Petri dish-sized, full-color picture related to an article in that issue. Color has also been introduced

\section{R. Guerrero $(\square)$}

Department of Microbiology,

University of Barcelona,

Avenida Diagonal 645,

08028 Barcelona, Spain

E-mail: guerrero@retemail.es

R. López

Centro de Investigaciones Biológicas,

CSIC, Madrid, Spain
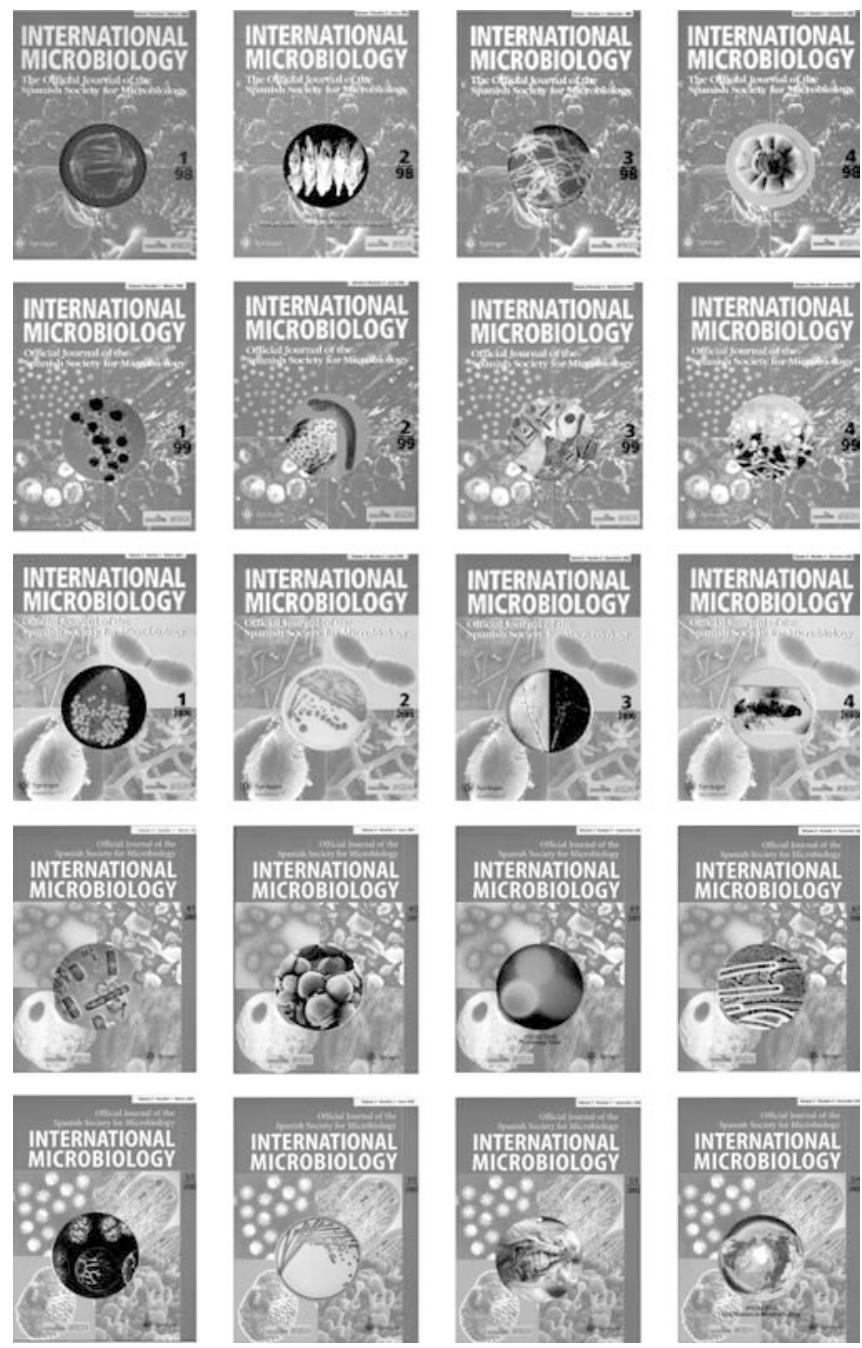

Fig. 1 Covers of International Microbiology published during the period 1998-2002 
Table 1 Articles published in International Microbiology in 1998-2002. CA "Complementary" articles (editorials, opinion, perspectives, biographies, book reviews, etc.), $R A$ research articles (reviews or primary research)

\begin{tabular}{|c|c|c|c|c|c|}
\hline Year & $\begin{array}{l}\text { Volume } \\
\text { (part) }\end{array}$ & $\begin{array}{l}\text { Number of pages } \\
\text { in RA }\end{array}$ & $\begin{array}{l}\text { Number of pages } \\
\text { in CA }\end{array}$ & Total pages & $\begin{array}{l}\text { Number } \\
\text { of articles }\end{array}$ \\
\hline \multirow[t]{5}{*}{1998} & $1(1)$ & 78 & 10 & & \\
\hline & 1(2) & 66 & 10 & & \\
\hline & $1(3)$ & 48 & 14 & & \\
\hline & 1(4) & 80 & 6 & & \\
\hline & Total & 272 & 40 & 312 & 52 \\
\hline \multirow[t]{5}{*}{1999} & $2(1)$ & 56 & 10 & & \\
\hline & $2(2)$ & 58 & 14 & & \\
\hline & $2(3)$ & 64 & 12 & & \\
\hline & 2(4) & 66 & 14 & & \\
\hline & Total & 244 & 50 & 294 & 46 \\
\hline \multirow[t]{5}{*}{2000} & $3(1)$ & 58 & 12 & & \\
\hline & $3(2)$ & 56 & 12 & & \\
\hline & $3(3)$ & 56 & 12 & & \\
\hline & $3(4)$ & 46 & 22 & & \\
\hline & Total & 216 & 58 & 274 & 44 \\
\hline \multirow[t]{5}{*}{2001} & $4(1)$ & 44 & 14 & & \\
\hline & $4(2)$ & 46 & 20 & & \\
\hline & $4(3)$ & 50 & 14 & & \\
\hline & $4(4)$ & 76 & 12 & & \\
\hline & Total & 216 & 60 & 276 & 38 \\
\hline \multirow[t]{5}{*}{2002} & $5(1)$ & 34 & 16 & & \\
\hline & $5(2)$ & 42 & 12 & & \\
\hline & $5(3)$ & 38 & 14 & & \\
\hline & $5(4)$ & 70 & 10 & & \\
\hline & Total & 184 & 52 & 236 & 35 \\
\hline
\end{tabular}

inside the journal, although authors wanting color figures in their articles must pay for the extra cost of printing them.

Applying the standard criteria of quality in the selection of articles has not been an easy task. Mainly because this implied rejecting articles by colleagues, who may feel annoyed because they do not always understand that the journal of their society may reject their articles. As a result, the number of originals received decreased. Once the SEM journal was consolidated as a modest journal, yet rigorous as for scientific quality, it recovered the flow of articles submitted for publication. However, a problem shared with other small scientific journals persists: it is difficult to understand why authors who make great efforts in the preparation of the articles they submit to "important" journals often fail to do so when they present their work to modest journals. Mistakes in the list of references, redundancy of information (in the text, figures, tables), differences between the data in the text and those in figures and tables, poor-quality illustrations, bad use of units, negligence in the use of the English language, et cetera are frequent in the articles submitted. In the case of junior authors, one thinks it is high time to make them know that researchers, in addition to doing research, must communicate the results of their research and that this must be made in a written form. They should know how to explain in a proper way the work they have done. Nevertheless, if reviewers consider that the scientific quality and interest of an original article submitted to International Microbiology make it worth publishing, the journal does not reject originals due to their careless preparation. Editing such aspects of articles is a hard task that should be recognized, mainly by the authors whose articles are highly improved.

Over the first 5 years (1998-1992) of the publication of International Microbiology, 20 issues were released, with a total of 215 articles and 1,392 pages (Table 1). Changing the paper size - the pages of the journal are now larger - and the layout has saved paper and optimized the space within the journal.

\section{The use of English}

Deciding the language of publication was not trivial. As mentioned [9], Rubens López introduced English in the journal, taking into account the advantages and the disadvantages of such a decision. If a researcher and his or her team aim to spread their work as far as possible, the use of English becomes necessary. In addition, English contributes to expand the diffusion of the journal itself. In fact, journal and authors benefit from this decision because their work expands beyond their local area, making it possible that more researchers get to know it and cite it in their own articles. Current scientific dynamics do not justify maintaining a product that is not of use to most of the community that sustains it; and this refers to the content as much as to the language.

When we started publishing Microbiología SEM, we aimed to publish a journal with reasonable scientific requirements that would end up having its whole content in the universal language of science, which is English. Nevertheless, not all SEM members agreed with that decision. In addition to this, when peer reviewers rejected an article by SEM members, some authors felt the refusal 
was offensive, even when the refusal included the reviewers' reasoned comments. Some authors even threatened not to send more manuscripts to the journal in future. This made things difficult, because the journal contents were supposed to consist mainly of articles by SEM members. We understood that research teams wanted to keep their best scientific products - written, of course, in English - for first-rank journals, but we aimed at receiving works with a minimum of quality. In the last few years of Microbiología SEM, we were able to have all research articles (reviews, primary research) published in English. After some initial doubts, all sections of International Microbiology were published in English.

\section{Peer review: the pros and the cons}

The boom in electronic publication has been changing a system of evaluation - peer review - which many authors find contradictory and which does not fit with the aim kindly attributed to it. This aim is to guarantee that the article evaluated fulfils the requirements of originality (it must not have been published previously), quality and scientific rigor in the performance and description of the work the authors have carried out. The implications of peer review are such that a strong group of medical-journal publishers - among them the American Medical Association, publisher of JAMA (Journal of the American Medical Association) and the British Medical Association, publisher of the British Medical Journal - hold a conference devoted to this topic every 4 years. These meetings discuss trends in authorship, conflicts of interest, proposals to improve the peer review process, biases and prejudices (mainly transcultural and geographic). Such debates aim to improve the system, to avoid undesirable cases of plagiarism, superiority, contradictory opinions and subjectivity. Peer review is considered to be necessary; yet it arouses great sound criticism [12, 13] and the organization of these meetings has also been criticized. In fact, "the union [of journals organizing peer-review meetings] manages very well to defend itself, which is logical because it is a group with its own interests and receives serious threats, including those derived from recent criticism of the arbitrariness of the editorial process and those due to the appearance of electronic journals 'rebellious' against peer review"; [1].

\section{Online journals and electronic publication}

At the third Congress on biomedical peer review (Prague, 1997), Ronald Laporte forecast the death of printed journals and even announced this would happen by 2020 [14]. Laporte's prediction may seem exaggerated. Electronic publication has stirred up the publishing world-both scientific and non-scientific - and has been the cause for the decline in the number of subscribers for some journals. Electronic publishing, however, might become a supplement of print publishing, which it might even reinforce in many cases. When searching articles in online journals, microbiologists often look for articles related to their own work and miss the opportunity to browse among the articles in other fields included in print journals. By doing so, they miss the opportunity to know new ideas or to improve their knowledge and training in general microbiology. For this reason, International Microbiology has insisted on having two versions: in print and online. SEM members receive the printed journal by mail; and each issue is not a mere series of unrelated articles, but a balanced exhibit of the different fields of interest to both authors and readers. Articles are arranged in a given order, depending on topics; and we try to ensure the complementary materials are also adequate and of interest. Because of the pleasure of reading print journals as they are produced, many researchers all over the world keep their subscriptions to printed versions of journals such as Science and Nature. By browsing them, we can take a general view of what is going on in science. This reading usually follows a quick glance through the contents received previously by e-mail [7].

The first experience of the SEM journal online was mentioned in the first article of this series [8]. In $\mathrm{Mi}$ crobiología $S E M$, that first step was described as a modest experiment whose aim was to bring the journal nearer to Spanish microbiologists [3]. The dramatic expansion of the Internet over the past decade made it necessary for any journal to have its own online version. The past 5 years since Microbiología SEM was first made available on the World Wide Web seem a long time now. In less than 1 year, the journal reached readers from more than 60 countries [3]. A major advantage of electronic journals is that the publishing process can be readily made because it needs neither printing nor distribution. Sometimes, however, the existence of an electronic version may delay the release of the printed edition, which is still the only one that many SEM members see. Big publishers have developed elaborate systems for authors and copy editing and also for electronic publication with which small companies and individuals cannot compete. It is becoming more and more necessary that some institutions or even governments, such as in Brazil, are provided with the technical means that allow them to compete with big publishers.

Publishing on the Internet is not difficult. Many servers provide their customers with space to set up their own websites, in some cases even for free. In addition, the most recent versions of text-processing software allow files to be made in HTML (hypertext markup language). Given that anyone able to access the Internet might publish one's own journal, electronic scientific publication must rely on mechanisms that guarantee the quality of the contents of online publications, especially when there is no the equivalent print version. The traditional peer-review process can be a 
guarantee. As mentioned above, however, there is currently no agreement about this kind of review. It has been suggested that the Internet could be a new means of publication of the results of one's own research without previous peer review-making this point clear to the readers, however. The scientific community would validate-or reject if that was the case - the results and conclusions published online. International Microbiology keeps the classic criterion of peer review prior to publication; and our final objective is to produce a printed journal with a nice format.

\section{The Institute for Scientific Information, Currrent Contents and the "impact factor"}

The "impact factor" (IF) and "science citation index" (SCI) are two relatively recent concepts that nowadays worry most researchers. They are an invention of Eugene Garfield, founder of the Institute for Scientific Information (ISI) in 1958. In the 19th century, a bibliographic index already existed in the field of jurisprudence and law. In addition, librarians had for many years evaluated journals by taking into account the citations of their articles in other publications. During the 1950s, the then young chemist Garfield searched for a system that allowed him to apply bibliographical citations as a means to index the literature in the different scientific fields without the need for human indexers [11]. Garfield set up both the SCI and the journals that have the general title Current Contents mainly to retrieve information. Nevertheless, their index databases, which are quantitative, have some characteristics that make them most suitable to be used as indicators of science and technology. They are multidisciplinary, comprising virtually all fields of both experimental and social sciences. In addition, they are exhaustive and comprise not only primary-research articles, but also any other kind of article published in the journals indexed, including editorials, review articles, obituaries and book reviews. Impact studies reveal that these other kinds of article must be taken into account because they may have a high impact and they provide links to localize discussion and debate on specific topics within different publications. Finally, each item indexed comprises all the data regarding both the citing and the cited article (authors, affiliations, addresses, etc.). All this makes analytical studies versatile: they can either focus on a minority subspecialty or search for a global perspective of science $[4,6]$.

Current Contents is the most widely known ISI publication. It comprises the indexes of the latest issues of many journals in a given scientific field and provides data on the major journals and books in different disciplines. It also contains the addresses of the article authors, in case the reader wishes to contact them. Currently, there are seven Current Contents devoted to the following fields: (1) agriculture, biology and environmental sciences, (2) arts and humanities, (3) clinical medicine, (4) engineering, computing and technology, (5) life sciences, (6) physical, chemical and earth sciences and (7) social and behavioral sciences. For each of the journals included in the ISI database (7,500 in 2001), articles, reviews, editorials, etc. are indexed in Current Contents. The database also comprises the whole bibliographic information of the journal indexed, including the abstracts, keywords and ISSN (international standard serial number). In its original print version, Current Contents was a publication of modest appearance, cheap paper, simple printing and small size that could be kept in the pocket and browsed at any moment of the day. In the early 1990s, the first electronic version was released, on diskette. It seemed a great advance, but the journal could be browsed only if a computer was available. Later on, the CD-ROM version was published, but this had the same disadvantage. ISI went further in their publication of Current Contents; and it is now an online database under the name ISI Current Contents Connect. In the total of 1,040 journals currently indexed in the Current Contents: Agriculture, Biology and Environmental Sciences, there are 85 journals on microbiology. Most of them are published in the United States (34) followed by the United Kingdom (21), the Netherlands, Germany and Japan (four each), France (two) and Austria, Canada, Denmark, Italy, Czech Republic and Switzerland (one each).

In 1997, the ISI database comprised more than 8,000 journals. High as this number may seem, it is only a small fraction of the journals published worldwide. Covering all scientific journals would be impractical economically and unnecessary, as analyses of scientific literature have shown. Currently around 150 journals account for about $50 \%$ of what is cited and $25 \%$ of what is published. A core of around 2,000 journals publishes about $95 \%$ of cited articles and $85 \%$ of published articles. This core, however, is not static and its basic composition changes continually [15].

ISI evaluates new journals and includes in its database those that can be useful to its subscribers. At the same time it deletes those that-according to ISI criteria-have become less useful. Every year, around 200 journals are evaluated, of which only $10-12 \%$ are selected. Both qualitative and quantitative factors are considered in the evaluation. The main factors considered are:

1. Basic journal standards. These include timelines of publication (this is of primary importance), conformity with international editorial conventions, English language in article titles, abstracts and keywords (an essential factor), application of the peer-review process (which indicates the quality of the research presented) and the adequacy of cited references.

2. Contents. ISI determines whether the content of a new journal will enrich the database in that topic or whether it is already adequately covered.

3. Internationality. ISI seeks to cover journals with an international diversity among authors, both in source 
articles and in cited articles, to meet the needs of its international subscriber base. In addition, ISI tries also to cover the best regional journals in each category.

4. Citation analysis. ISI evaluators take into account both the citation of articles published in the journals under evaluation and the discipline. In fact, small fields do not generate many articles or citations. In others, however, it may take a relatively long time for an article to attract a meaningful number of citations. For established journals, the overall citation rate, IF and immediacy index are used. In the case of brandnew journals, the publishing record of the journal's authors and editorial board members is considered.

Most journals are evaluated at the request of the editors of the journal itself. This it not, however, the only way to start this process. ISI welcomes suggestions and recommendations from third parties. Those recommending a journal for evaluation must provide ISI with the full name of the journal, its ISSN, the name and address of the editor and the journal's publisher. If possible, they must also send the most current issue of the journal and then the next two or three issues as soon as they are published.

The IF is a quantitative tool that allows the evaluation of a journal by comparing it with other publications. It measures the frequency with which the average article in a journal is cited over a given period. The IF of a journal, published annually in the Journal Citations Reports (another ISI publication) is the ratio between the number of citations and citable items in a given period. It is calculated by taking the number of all citations of the articles published in a given journal during the year considered and dividing this by the number of articles published in that same journal during the previous 2 years.

IF has several applications. It is most frequently used for commercial purposes, because it helps publishers to know the rank of their journals among the other journals in the same field. It also serves advertisers, who explore the potential market for their products. It is very useful also to librarians in the management of library journal collections, helping them choose the most suitable journals. For some time, however, the IF has also been used to assess the scientific productivity of an individual researcher or team, by considering the IF of the journals in which the researchers publish their articles. Substituting this kind of "evaluation" for any other is a great mistake. In fact, the criteria for the evaluation of different kinds of publications and disciplines cannot be the same. The IF should not be used to assess the individual work of researchers or to compare journals in different scientific fields $[2,5,8]$. The scientific value of a candidate tends to be analyzed "objectively" and quantitatively by adding up the FI of his or her articles. As we have seen above, this is a mistake because the IF refers to the journal as a whole and not to the items that make it up. In addition, evaluators should not use the same criteria to assess the significance of research carried out in different fields. Researchers, on their part, should not try to inflate the number of citations of their own articles by self-citing, nor should they choose journals in which to present their work on the grounds of the journal IF. The right evaluation of the quality of the scientific production of a researcher considered individually can be achieved only by reading all of his or her individual articles. This approach, however, requires not only the ability in a given field - that of the author-but also the time to do it, two things that most evaluators lack nowadays [8].

\section{International projection of the SEM journal}

We do not know whether the editors of Microbiologia Española ever requested the inclusion of their journal in Current Contents. In 1986, Rubens López did it for Microbiología SEM, but the journal was not accepted. In 1999, International Microbiology also requested to be considered for coverage, which implied an evaluation process that would take a minimum of 2 years. In July 2000, R. Guerrero visited the ISI headquarters in Philadelphia and his impression was that achieving the coverage of the journal by those longed-for indexes would not be a great problem at the end of the evaluation process. International Microbiology was being evaluated and we could see a great increase in the number of citations of the journal's articles (Fig. 2).

That visit provided much information on the journal visibility, thanks to the statistical analysis that the ISI had made. Things are not so clear-cut, however, and experience shows that only a candid mind could not be aware of the influence that big publishing companies exert on ISI: publishers act as lobbies and their influence goes in parallel with their economic power. In its editorial of 10 January, 2002, Nature uncovered some inaccuracies detected in the ISI citation indexes. Of course, ISI cannot be responsible for the uses others make of the statistics they produce. However,

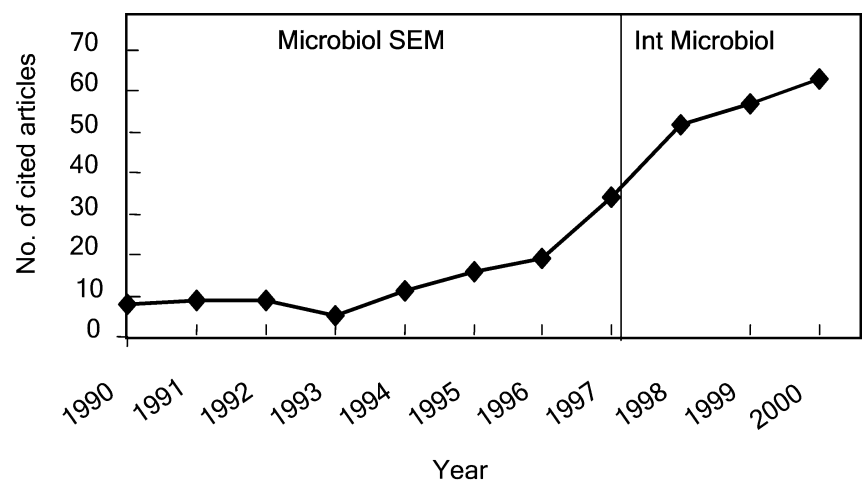

Fig. 2 Number of articles in Microbiología SEM and International Microbiology cited by other journals during the period from January 1990 to July 2000 
ISI - now owned by the strong publishing company Thomson Corporation - is accountable for the accuracy - or inaccuracy - of the data it publishes. In statistics published by ISI, the Nature paper describing the sequencing of the human genome had citation counts so low that it was not included among articles with the highest impact and influence in biology, known as "hot papers". Nature staff analyzed the ISI data and they found that citations to that paper had been grossly undercounted. ISI admitted the error and amended its statistics, which made the genome paper go to the top of the "hot papers" list [2]. In 1996, López Piñero reported that the technical flaws of the methods used for statistical analyses based on citations caused about $25 \%$ of all errors [10].

Surely this has not always happened, nor was this the idea of Eugene Garfield, leader of scientific information, when in 1955 he decided to gather scientific literature in a database. Nowadays, that database is the most important in the world; and the dream-or the nightmare - of many scientific publishers and editors is that it covers their journals. For some time, however, the editorial world has been undergoing enormous changes that have disrupted its traditional characteristics. Once, the content and quality of the product marketed were the grounds for business; and the company profits did not depend only on marketing criteria, as is the custom now.

The framework that comprises the minimal prerequisites to improve the quality of the SEM journal has been the same since 1985 . The quality of a journal does not depend on the country in which it is published nor on the geographical origin of its authors. A journal published in a country that is not among the scientific first rank can still achieve international recognition. Individual articles - formerly only reprints - can reach remote locations where the whole journal will surely never arrive. We found it amazing that two articles that many would consider to be "minor" articles because they were published in the SEM journal were cited in first-rank publications in the field of microbiology. R. López found that an article on bacterial polysaccharide production that he wrote in 1968 for Microbiología Española (López and Becking, Microbiol Esp 21:53-75) was cited in the following editions of Bergey'sl Manua. R. Guerrero found that an article on specific density he co-authored for the first issue of Microbiologia SEM in 1985 (Guerrero et al., Microbiol SEM 1:53-65) was cited in major microbiology journals.

The dedication of so many people to the SEM journal has hidden the aspirations and difficulties that must be made public to guide colleagues who now take responsibilities on the SEM Executive Board. The history of a journal that, with all its ups and downs, is now more than 55 years old should not depend on the caprice of some people who consider that publishing this journal is not a profitable investment. Were we to make only what is profitable, the SEM itself would have never been founded. We must remember that the efforts of those who "make" the journal-not only editors but also
Table 2 Origin, besides Spain, of the articles published in International Microbiology in 1998-2002

\begin{tabular}{lc}
\hline Country & Number of articles \\
\hline United States & 26 \\
Germany & 17 \\
France & 13 \\
Canada & 9 \\
Argentina & 6 \\
Mexico & 5 \\
Russia & 5 \\
Venezuela & 4 \\
Brazil & 4 \\
Netherlands & 2 \\
Italy & 2 \\
United Kingdom & 2 \\
Norway & 2 \\
Israel & 2 \\
Nigeria & 2 \\
Chile, Colombia, Cuba, Czech & 1 \\
Republic, Japan, Turkey, & \\
Switzerland, South Africa & \\
\hline
\end{tabular}

members of the various boards, reviewers and authors who submit their articles to the SEM journal despite it not being covered by Current Contents - are not wasted if the SEM members read the journal and appreciate it, if the journal conveys to SEM members the generalist intention of the Society and its vision of microbiology as an integrating science (gathering all aspects of research, technology, teaching and culture) and if it serves as a means to present internationally the existence of the SEM and its activities. Accordingly, originals arrive not only from Spain, but also from other countries (Table 2).

We must recognize the work done by reviewers-anonymous, according to the peer-review model we chose-whose help with their opinions and advice is acknowledged. Another significant component of the journal is its Publication Board, which since 1993 has collaborated by spreading articles and editorials and suggesting topics for monographic issues, among other tasks. We have also the already mentioned Editorial Board, of great quality. The differences both in the geographical origin and in the field of expertise of its members allow the prevention of "influences" and help to spread the journal abroad.

The rank of a journal among a vast amount of other publications in a given discipline - in our case, microbiology - depends not only on the efforts of the editor, the Editorial Board and the scientific society behind the journal. Its status depends also on factors such as competition with other journals in the same field, which makes it necessary to opt for quality and to choose the universal language for the spreading of science-English. Coverage of the journal by the ISI indexes is a necessary goal, yet it is expensive both economically and in terms of personal effort. Scientific quality, timelines of publication, correction of the language and having internationally recognized experts on the Editorial Board are prerequisites. Nevertheless, this 
is not enough; and high quality in the reproduction of the texts and illustrations, an attractive cover page and a suitable layout are other features that must be taken into account and are costly both in terms of money and effort. To carry out this venture, the support, encouragement and recognition of those for whom the product is meant - the SEM members - is needed. In addition, SEM members are also the main providers of raw material-articles - to make the journal.

The journal also reaches microbiologists who are not SEM members. In many cases, it is the only link between readers and the SEM. The publisher of Microbiologia $S E M$ - Editorial Garsi-succeeded in getting the journal covered by several international indexes (to our knowledge, Biosis, Chemical Abstracts, Medline, Index Medicus, Excerpta Medica). The steps taken by Springer-Verlag can be decisive for International Microbiology to be covered also by these and other international indexes. Regardless of the time this may take, many things will change, due to the boom in electronic publication and the dramatic scientific diffusion through the Internet that will - either in the short or the long term - affect the IF itself and the peer-review process. Until recently, many journals made their whole contents available only to subscribers, whereas "visitors" were able to read only the abstracts of articles. Publishers have realized that maintaining such a restrictive policy produces a boomerang effect. In fact, they are restricting the potential citation of the articles in their journals by authors who cannot access the print version. This, along with the application signed in 2001 by some tens of thousands of scientists to claim the free availability of the online contents of journals in a period no longer than 6 months after publication, has started to produce some results. Anyway, it may not greatly affect several of the medical publishers that make reprints of some articles not in tens or hundreds but in hundreds of thousands (paid, of course, by the pharmaceutical companies that also paid for the research work described) [12].

The IF can be affected by the number of visits to the websites of different publications, which can often be made from very distant locations - in many cases from locations where access to the printed journal is not possible. The quantification of these visits and the citation of online articles will surely influence how to rank journals and articles. The future of International Microbiology will depend on the circumstances at each moment. The circumstances, however, will reflect the attitude and the aptitude of those backing its continuity. Such attitude and aptitude will help to overcome both external restraints, including competitiveness and marketing factors, and internal hindrances, including the low consideration we tend to give to our own things, in this case the journal. We have never heard negative comments on the SEM journal by foreign researchers. Many of them may have not known the journal, but when someone obtains an item from the journal - either a reprinted article or an article downloaded from the online version-his or her opinion is usually good. In addition, other scientific journals that still survive in Spain have praised ours.

With these articles, we have tried to write a short history of the SEM journals as a whole. We have tried also to pay a small homage to those who quietly and modestly devoted time and effort to this task and had to face the anger and lack of understanding of many colleagues. Thanks to them, we have now a journal worthy of praise and support, a vehicle to convey the generalist, integrating goal of the SEM and a card of international presentation of which our Society can be proud. We owe what we have now to the staunchness of so many people and their ability to make possible what was sometimes improbable and to make real what was barely possible, to their excitement to achieve what seemed far beyond their reach. As the Valencian poet Ausiàs March (13971459) wrote, "what is not made by force / nor by grace nor by wisdom / is achieved by resistance / by the force of willingness."

Acknowledgements This work of pseudohistorians could not have been written without the help of the various persons who provided us with data or helped to search for information, especially Ernesto García, Mercè Piqueras and Carmen Chica, who have devoted so much time and effort to the SEM journal(s) for many years. We also acknowledge the help of Mercè Piqueras and Frances Luttikhuizen in the preparation of the English version.

\section{References}

1. Camí J (1998) A tale of a disappointment (in Spanish). Quark $10: 8-11$

2. Editor (2002) Errors in citation statistics. Nature 415:101

3. García-Gil J (1997) A year of Microbiología SEM in Internet (in Spanish). Microbiol SEM 13:517-522

4. Garfield E (1994) The concept of citation indexing: a unique and innovative tool for navigating the research literature.http:// www.isinet.com/hot/essays/1.html (Published originally in Current Contents, printed version, 3 January 1994)

5. Garfield E (1994) The impact factor.http://www.isinet.com hot/essays/7.html (Published originally in Current Contents, printed version, 20 June 1994)

6. Garfield E, Welljams-Dorof A (1992) Citation data: their use as quantitative indicators for science and technology evaluation and policymaking. Sci Public Policy 19:321-327

7. Guédon JC (2000) Digitizing scientific journals (in Spanish)? Mundo Cient 218:58-59

8. Guerrero R (2001) Misuse and abuse of journal impact factors. Eur Sci Edit 27:58-59

9. Guerrero R, López R (2003) A brief history of the journal(s) of the SEM: resisting staunchly against improbability. I. From 1947 to 1997 . Int Microbiol 6:69-73

10. López Piñero JM (1996) Indicators of scientific activity. Microbiol SEM 12:469-472

11. Piqueras M (2001) Review of "The web of knowledge. A festschrift in honor of Eugene Garfield". Int Microbiol 4:119-120

12. Piqueras M (2001) Peer review, the Achilles heel of scientific publication (in Spanish)? Quark 21:116-117

13. Semir V de (1996) What is newsworthy? Lancet 347:1063-1066

14. Sharp D (2000) Threats to the future of print journals (editorial). Eur Sci Edit 26:75

15. Testa J (1997) The ISI database: the journal selection process.http://www.isinet.com/essays/199701.html (visited 15 February 2003) 